\title{
Economic Convergence in the European Union: How does Malta Fit in?
}

\author{
Melchior Vella ${ }^{1}$ \\ ${ }^{1}$ Department of Economics, Unviersity of Malta, Msida, Malta \\ Correspondence: Melchior Vella, Department of Economics, University of Malta, Msida, Malta. E-mail: \\ melchior.vella.09@um.edu.mt
}

Received: December 20, 2014 Accepted: January 13, 2015 Online Published: February 25, 2015

doi:10.5539/res.v7n3p229 URL: http://dx.doi.org/10.5539/res.v7n3p229

\begin{abstract}
The paper tests the hypothesis that developing member states of the European Union converge to richer countries. On the basis of a Cobb-Douglas production function this study estimates beta convergence, and sigma convergence, utilising data from the $28 \mathrm{EU}$ member countries. The results confirm the hypothesis and indicate that poor countries grow faster than rich economies in terms of per capita income and the convergence process for Malta is slower. This finding has important implications for transition EU member states, including that Malta needs to overcome several constraints in the transitional phase to increase the steady state level.
\end{abstract}

Keywords: absolute convergence, conditional convergence, divergence, $\beta$ convergence, $\sigma$ convergence, spatial dimension

\section{Introduction}

Economic convergence has always been associated with one of the major benefits of EU membership given that economic and social cohesion is one of the objectives specified in the EU Treaty. Empirical literature shows that less developed countries tend to grow more rapidly than wealthier countries. Such that, in time, all economies converge in terms of per capita GDP (Note 1). Nonetheless, it has also been acknowledged that despite trends of convergence, substantial income levels differentials still persist today across European countries (Note 2).

There is extensive empirical growth literature that examines the convergence hypothesis over an extended period. Following the seminal work of Baumol (1986), which found that convergence amongst industrialised countries was almost perfect, the DeLong (1988) critique, and the extensions by Barro and Sala-i-Martin (1991, 1992) and Mankiw et al. (1992), the convergence issue attracted considerable attention thereafter in empirical literature.

Convergence is well documented for EU15, and membership in the customs union proved to be an important factor, though this is not an automatic outcome. Consequently, ever since the enlargement of the EU in 2004, many researchers covered the new member states (NMS), prominently the Central Eastern European (CEE) countries, in the convergence debate (Kaitila, 2004; Varblane \& Vahter, 2005; Prochniak, 2008; Vojinović \& Oplotnik, 2008; Vojinović et al., 2010). The literature generally reports that the catching-up process is sensitive to both the study period and the chosen cluster of countries.

Malta is the smallest EU member state, with a population of less than half a million, which acceded to the EU on May 2004 and adopted the euro in January 2008. One of the characteristics of small states relates to the limited ability to reap the benefits of scale economies (Briguglio \& Vella, 2015), and indeed, the major arguments in favour of Malta's accession to the EU related to opportunities in having a larger market and free import barriers against Maltese products. In addition, it was argued that Malta could also attract foreign direct investment from non-members wanting to use Malta as a means of penetrating European markets (Briguglio, 2011). Consequently, from an economic point of view, improvements in per capita income and lower income disparities with member states of the EU were essential objectives of Malta's integration in the EU.

The paper is intended to serve two goals. First, this paper focuses on NMS (Note 3) of the European Union, and tests the hypothesis that the less developed member states experience economic convergence. In order to do this, the paper compares GDP per capita growth rates in purchasing power standard (PPS) (Note 4) for those of the remaining EU28 countries utilising annual data averaged for the period ranging from 2000 to 2012. Second, this paper studies how Malta fits in the convergence process after a decade of EU membership on which little 
literature has been published.

Based on the evidence from EU member states, Section 2 reviews the catching-up process and discusses the empirical evidence of the potential determinants of convergence. Section 3 presents the methodology used, whilst Section 4 discusses the empirical results of convergence for Malta. Concluding remarks derived from the results are presented in Section 5.

\section{Economic Cohesion}

\subsection{Defining Economic Convergence}

Neoclassical growth models typically assume that poorer countries tend to grow faster than richer ones. Consequently, growth in per capita GDP is negatively related to the initial level of per capita output. It is generally argued that economic convergence occurs because less developed countries have less capital stock, and therefore higher marginal returns on capital (Solow, 1956). Advancements in technology (Tamura, 1991) and human capital (Romer, 1990) are also drivers of economic convergence, as the import of technology and human capital from richer countries help less developed countries to catch-up with developed countries.

Over time, countries converge to a steady state, which is defined as the equilibrium position of an economy. If a country is at its steady state it means that per capita income is growing at a 'balanced' or constant growth rate-normally equal to the rate of technological progress. In fact, one of the implications of a neoclassical growth model is that if a poor and a rich country are at their respective low and high steady state positions, then a poor nation cannot reach the same per capita output level as that found in a rich country. An economy at a low steady state level cannot converge to a higher level of income when it has particularly low levels of physical and human capital and low level of technological advancement. Rather, its growth rate behaves according to the changing level of capital stock and employment rate, amongst other things. In other words, a poor country converges if it is in transition towards a higher steady state, only if the level of capital stock and employment rate, augmented by technology, are rising.

Convergence can be measured in two ways. The first measure is known as $\beta$ convergence, which tests the hypothesis that per capita economic growth is inversely related to the starting level of output per capita (Barro et al., 1991). Another measure is $\sigma$ convergence which occurs when the dispersion of per capita income falls over time (Barro \& Xavier, 1992).

$\beta$ convergence can be generally classified into absolute and conditional convergence. Absolute convergence refers to a tendency for two or more economies to become more similar in respect of per capita incomes. The implication of this is that economies converge to a common steady state. However, if per capita income of different countries converge to their respective steady state, then conditional convergence is set to take place (Mankiw et al., 1992). The implication is that structural characteristics and not initial income determine the level of steady state per capita output because each country is converging towards its own long-run state.

An important characteristic of convergence is that while $\beta$ convergence is a necessary condition for convergence, it is not a sufficient condition for $\sigma$ convergence. Intuitively, economies can have $\beta$ convergence, while, at the same time, random shocks are pushing them apart. Examples are shocks to output or prices that tend to affect economies with different per capita income level asymmetrically. Other examples where $\beta$ convergence does not imply $\sigma$ convergence arise when economies with the same level of per capita income have different steady state levels. The initial income gap will be zero but disparity will grow over time as a country with the highest steady state value grows relatively faster. 


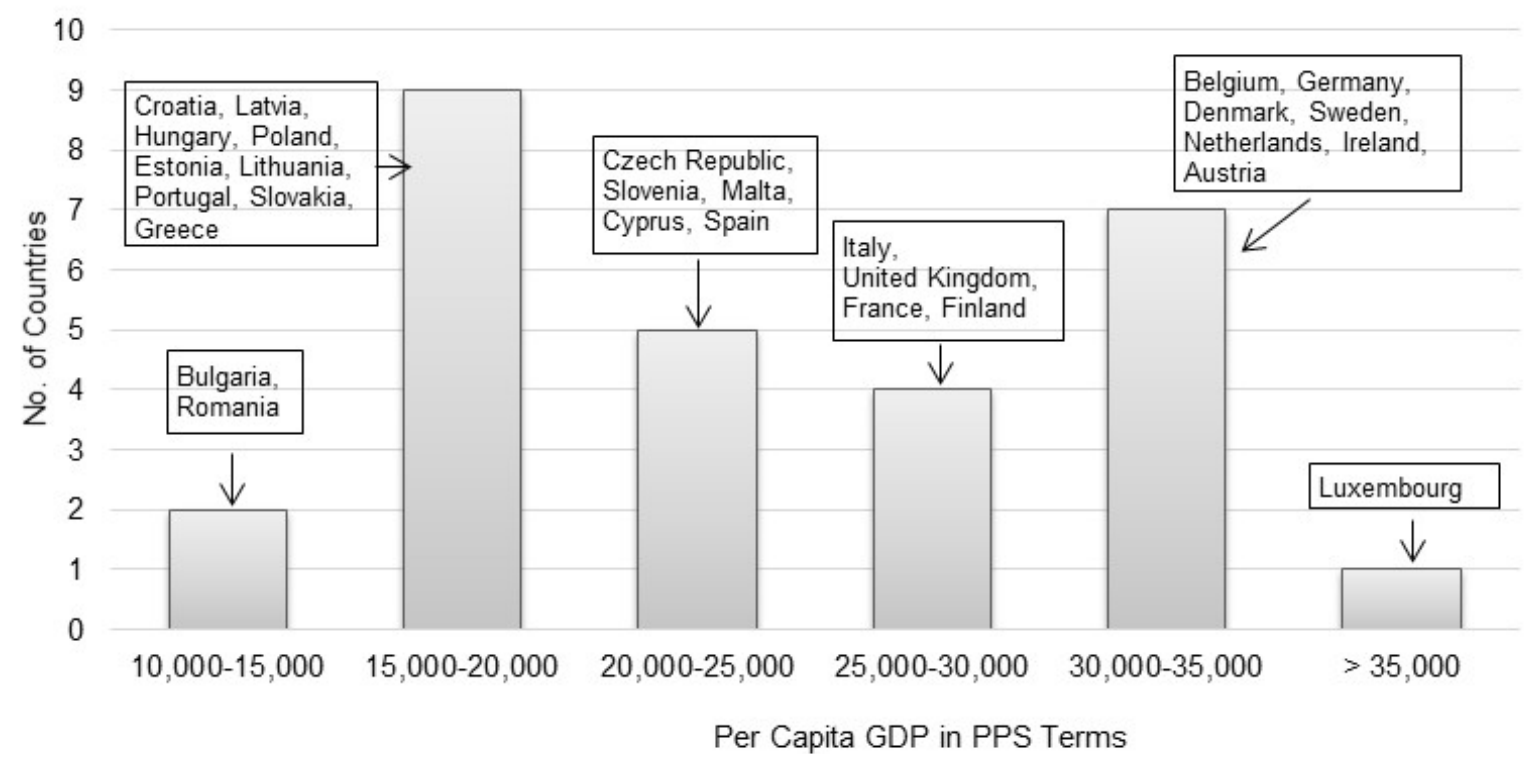

Figure 1. Histogram for per capita GDP in PPS terms in 2012

\subsection{Per Capita Income Disparities in EU28}

Substantial income levels differences exist between the EU member states, which, despite some degree of convergence, have persisted over the past decade between the former EU15 and the enlarged EU. By 2012, average GDP per capita in PPS in NMS was approximately $40 \%$ below the average of the former EU15. Figure 1 shows a histogram for real per capita GDP for EU28 in 2012. The richest countries are members of EU15 group of countries, with the exception of Greece, Portugal and Spain. The two small island states, Malta and Cyprus, are at the middle range of per capita GDP levels, while the majority of countries with low income levels consist of a mixture of CEE and Baltic countries (Note 5). The mean value of EU28 corresponds to per capita GDP in PPS of 25,000, and the coefficient of variation (CV) of the real per capita GDP-a measure of proportionate dispersion-was 0.41 , meaning that the standard deviation is equal to $41 \%$ of the average. Bulgaria displayed the lowest level of GDP per capita, at less than $52 \%$ of the EU28 average. Luxembourg recorded the highest level of per capita GDP (Note 6) followed by the Netherlands, at 30\% above average. Malta recorded GDP per capita in PPS of 22,000, 12\% below EU28 average. In 2012 three EU15 countries-Greece, Portugal and Spain-had a per capita income level below that of EU28 average, approximately $12 \%$ below that of Malta.

\subsection{Malta in the Convergence Process}

The per capita performance of the Maltese economy during the 2000 to 2012 period grew, on average, by $2.4 \%$ per annum. As observed in Vojinović et al. (2010, p. 318) 'Malta recorded extremely slow annual economic growth' well before as well as after acceding to the EU. A possible implication of a slow growth rate of per capita income is that the income gap to EU15 becomes broader because of a fragile speed of convergence.

The catch-up gap rate for NMS can be measured as follows

$$
\frac{\left(y_{i, t}-y_{t}^{*}\right)-\left(y_{i, t-1}-y_{t-1}^{*}\right)}{\left(y_{i, t-1}-y_{t-1}^{*}\right)} * 100
$$

where $y_{i, t}$ is the level of per capita GDP in PPS for converging country $i$ at current time $t$, and $y_{t}{ }^{*}$ is the average value of $y_{t}$ for EU15 countries. In this case, a positive catch-up gap rate means that the gap between a country and EU15 is widening while a negative gap rate indicates a shrinking gap.

The evidence presented in Table 1 shows that during the 2000-2007 period, while NMS converged strongly to EU15 average, Malta's catching-up process was less positive as the income level gap relative to EU15 countries widened. Indeed, apart from Italy, Malta registered the lowest real economic growth per inhabitant. It was only due to Malta's resilience to the global crisis that the main change that the economic crisis in 2008 brought about was the rapid catch-up for Malta relative to NMS. This development is mainly due to lower per capita growth amongst European peers. Nevertheless, on average, the degree of dispersion between Malta and EU15 remains 
notable in the period 2000-2012.

Table 1. Catch-up gap rate, new member states, 2000-2012

\begin{tabular}{lrrrrrrrrrrrrrr}
\hline & $\mathbf{2 0 0 0}$ & $\mathbf{2 0 0 1}$ & $\mathbf{2 0 0 2}$ & $\mathbf{2 0 0 3}$ & $\mathbf{2 0 0 4}$ & $\mathbf{2 0 0 5}$ & $\mathbf{2 0 0 6}$ & $\mathbf{2 0 0 7}$ & $\mathbf{2 0 0 8}$ & $\mathbf{2 0 0 9}$ & $\mathbf{2 0 1 0}$ & $\mathbf{2 0 1 1}$ & $\mathbf{2 0 1 2}$ & Avg \\
\hline BG & 8.3 & 0.4 & 2.2 & -0.4 & 3.3 & 1.1 & 4.8 & 3.1 & -6.0 & -8.1 & 4.4 & -1.0 & -0.4 & 0.9 \\
CZ & 13.3 & -3.2 & 4.1 & -4.6 & 1.3 & 0.1 & 6.3 & -0.6 & 0.3 & -13.3 & 10.8 & 1.0 & -0.7 & 1.1 \\
EE & 6.4 & -0.2 & 0.0 & -5.1 & 0.9 & -3.4 & -0.5 & -1.9 & -0.5 & 0.6 & 4.4 & -7.6 & -3.6 & -0.8 \\
HR & 7.6 & 0.5 & -0.6 & -2.0 & 3.0 & 1.4 & 5.7 & 0.9 & -6.2 & -6.2 & 10.9 & 1.4 & -0.5 & 1.2 \\
CY & 9.4 & -7.5 & 10.7 & 1.6 & -1.0 & -4.0 & 7.6 & 1.8 & -21.6 & -13.5 & 21.0 & 11.2 & 6.0 & 1.7 \\
LV & 9.1 & -0.8 & 1.2 & -2.2 & 1.4 & -0.6 & 2.0 & -0.9 & -3.9 & -1.9 & 3.1 & -4.8 & -6.9 & -0.4 \\
LT & 8.8 & -1.4 & 1.3 & -5.4 & 2.8 & -1.9 & 2.8 & -1.6 & -6.2 & 1.9 & -1.3 & -7.4 & -7.8 & -1.2 \\
HU & 9.0 & -4.7 & 0.1 & -0.6 & 4.1 & 2.3 & 7.6 & 8.5 & -6.1 & -10.8 & 3.8 & -0.7 & 1.6 & 1.1 \\
MT & 4.5 & 13.2 & 3.7 & 1.4 & 11.8 & 1.1 & 11.5 & 5.8 & -9.2 & -16.2 & 0.0 & 3.5 & 0.3 & 2.4 \\
PL & 9.9 & 2.5 & 3.4 & 0.8 & 2.7 & 1.9 & 5.7 & 2.0 & -4.9 & -13.8 & 0.7 & -2.0 & -2.6 & 0.5 \\
RO & 9.4 & 0.4 & 2.7 & -0.9 & 1.7 & 2.6 & 2.2 & 1.7 & -8.0 & -8.4 & 4.0 & 1.1 & -1.5 & 0.5 \\
SI & 14.8 & -0.4 & 0.1 & -2.1 & -2.1 & 0.1 & 7.7 & 2.7 & -10.6 & 3.5 & 10.7 & 1.1 & 1.3 & 2.1 \\
SK & 11.0 & -1.6 & 1.5 & -0.6 & 3.0 & -2.0 & 2.3 & -2.5 & -10.9 & -8.7 & 1.7 & -0.8 & -1.5 & -0.7 \\
NMS & 9.3 & -0.2 & 2.3 & -1.6 & 2.5 & -0.1 & 5.0 & 1.5 & -7.2 & -7.3 & 5.7 & -0.4 & -1.2 & 0.6 \\
\hline$*$
\end{tabular}

*Average

A distinguishing feature of Malta is that its catch-up gap rate has been one of the most volatile amongst NMS. This could be due to the fact that Malta is inherently exposed to conditions beyond its control since it has small population size and high dependence on international trade (Note 7).

Another observation that emerges from the catch-up gap rate is that the pace of convergence has been rather uneven across countries over different years. The early 2000s had periods when no catch-up occurred for NMS. In other years, however, the evidence is more varied across these countries.

While these results provide a first impression of the EU experience over the last decade, a more rigorous analysis is needed to determine (1) whether, over the long run, convergence has indeed been taking place and (2) if so, whether it has been large enough to close income disparity.

\section{Methodology}

The approach adopted in this study is to use a Cobb-Douglas production function in intensive form to measure $\beta$ convergence (Note 8). $\sigma$ convergence can be measured by the $\mathrm{CV}$ of the cross-country per capita income (Note 9).

\subsection{Specification of $\beta$ Convergence}

Based on cross-sectional data, Baumol (1986) implemented a method of testing $\beta$ convergence derived from a Cobb-Douglas production function, which can be specified as follows

$$
g_{i, t}=\alpha_{i}+\beta \ln y_{i, 0}+\varepsilon_{i, t}
$$

where $g_{t}$ is the annual growth rate between $t=0$ and $t=T, y_{0}$ is output per capita at $t=0$ for each country $i$. For simplicity it is assumed that $\alpha_{i}$ is fixed and represents the fundamentals of each country. $\quad i, t$ is the disturbance term which is assumed to have zero mean and the constant variance and is independent for all economies.

Since $g_{t} \simeq \ln y_{t}$-lny $y_{0}$, Equation (2) can be refined as follows

$$
\ln y_{i, t}=\alpha X_{i, t}^{\prime}+(1+\beta) \ln y_{i, 0}+\varepsilon_{i, t}
$$

where $X_{t}$ ' is a vector of variables which captures variables such as stock of physical and human capital in each country $i$. It is expected that $(1+\beta)<0, \beta>0$, because the annual average growth rate of GDP per capita over the period $T$ is inversely correlated to the initial per capita GDP in the year $t_{0}$. Then if $\alpha X_{t}^{\prime}$ ' is the same across all $i$-that is, all countries converge to the same income per capita-then it is said to indicate absolute $\beta$ convergence. 
Conditional convergence, however, is present if $X_{t}$ ' varies across countries, such that each country converges to its own respective steady state level.

The estimated regression is given by (Note 10)

$$
\frac{1}{T} \ln \frac{y_{i T}}{y_{i, 0}}=\alpha_{0}+\frac{1-e^{\beta T}}{T} \cdot \ln y_{i, 0}+\varepsilon_{i, t}
$$

where $T$ is the length of the interval. Equation (4) can be expressed as follows for estimation purposes

$$
\frac{1}{T} \ln \frac{y_{i, T}}{y_{i, 0}}=\alpha_{0}+\alpha_{1} \ln y_{i, 0}+\varepsilon_{i, t}
$$

where $\alpha_{1}=\left[\left(1-e^{-\beta t}\right) T\right]$. In Equation (5) all other explanatory variables, which may influence per capita GDP growth rate, are not being accounted for, and hence reflect absolute $\beta$ convergence. The conditional $\beta$ convergence hypothesis can be tested if Equation (5) is augmented by a vector of independent variables to condition the steady state of the respective countries.

The Barro and Sala-i-Martin (1992) specification implies that the speed of convergence, $\beta$, is given by

$$
\beta=-\frac{1}{T} \ln \left(1+\alpha_{1} T\right)
$$

In Equation (6), the coefficient of $\ln y_{i, 0}$ declines with duration of the time period, for a given value of $\beta$. Therefore, as $T$ increases, the effect of the initial position on the average growth rate declines.

\subsection{Specification of $\sigma$ Convergence}

The income differentiation can be measured by the CV of per capita GDP between countries. A decreasing value of $\mathrm{CV}$ indicates $\sigma$ convergence, an increasing value shows income dispersion, and a stable income dispersion is reflected by a constant value of CV. The $\sigma$ convergence hypothesis can be tested by estimating a linear time trend of the dispersion of income levels among countries, $I D_{y, t}$

$$
I D_{y, t}=\alpha_{0}+\alpha_{1} t+\varepsilon_{t}
$$

If parameter $\alpha_{1}$ is negative, $\sigma$ convergence exists because a linear time trend of the dispersion of income levels among countries, $t=1, \ldots, 11$, is negatively related to $I D_{y, t}$.

Barro and Sala-i-Martin (1995) show that income dispersion at steady state, $I D^{*}$, can be expressed as follows

$$
I D_{y}^{*}=\frac{\sigma_{u}^{2}}{\left[1-(1-\beta)^{2}\right]}
$$

where $\sigma_{u}^{2}$ denotes random shocks. Equation (8) implies that convergence, in the sense that less developed countries tend to grow faster than developed countries, does not necessarily implicate that $I D_{y, t}$ declines over time. In fact, $I D_{y}{ }^{*}$ can remain positive even if $\beta$ is greater than 0 , as long as $\sigma_{u}{ }^{2}$ is positive. This implies that rising income dispersion between countries can occur with $\beta$ convergence, meaning that while $\beta$ convergence is a necessary condition for $\sigma$ convergence, it is not sufficient for convergence to actually substantiate as long as the effect of $\beta$ is outweighed by transitory shocks to the economy, $\sigma^{2}$. Cross-economy variance of per capita income can be reduced the higher the strength of the convergence effect, $\beta$, and the lower the variance, $\sigma_{u}^{2}$.

\section{Data Used and Estimation Method}

Convergence is investigated for a cross-section of EU28 countries utilising annual data on per capita GDP in PPS (y) with data averaged over the periods of seven and twelve years (2000 to 2007, and 2000 to 2012) to reflect the main change in the catch-up gap rate that the economic crisis in 2008 brought about for Malta (Note 11). The data is sourced from the EUROSTAT database (see data in appendix).

A priori, one expects that, in Equation (5), $\alpha_{1}$ takes a negative sign given that poorer countries grow more rapidly than rich ones. Malta's convergence rate was estimated by introducing a multiplicative dummy variable for Malta in Equation (5). By using a multiplicative dummy variable we can tell whether the convergence rate for Malta is statistically different from the European average, with a negative value indicating that the rate of convergence is slower, and vice versa.

\subsection{Segmenting the Period}

For a better understanding of cross-country income convergence, it is useful to examine cross-country growth patterns during the pre-crisis period (2000-2007), and the crisis era (2008-2012). As illustrated in Figure 2, Malta narrowed the catch-up gap rate ever since 2000 in relation to the initial level of per capita income in PPS (Note 
12).

The average growth rate of real per capita GDP from 2000 to 2007 and from 2000 to 2012 is negatively related to the 2000 level of real per capita GDP. Both graphs suggest that, with the exception of Luxembourg, between 2000 and 2012 the estimated relationship is not driven by obvious outlier observations and fits the linear extrapolation very well. Moreover, whereas from 2000 to 2012 Malta recorded a per capita income growth rate like in Cyprus, Slovenia, Greece, and Portugal, during 2000 to 2007 period, Malta registered a comparatively low growth rate. This suggests that in the aftermath of the financial and debt crisis, Malta has improved its position, compared to EU member states. Consequently, both periods are to be considered in estimating convergence, so to capture the effect from the change in pattern in Malta's catch-up gap rate that occurred in 2008.

\subsection{Incorporating Conditions}

It needs to be emphasised that EU member states may be heterogeneous (Marques, 2011; Eickmeiera \& Breitung, 2012; Chapsa \& Katrakilidis, 2014; Firgo \& Huber, 2014) (Note 13). If EU member states have different economic structures, the assumption that all economies have the same parameters, and therefore the same steady state positions, can be dropped. This implies that if steady state positions differ-say due to different saving rates, years spent in education or access to technology-the logic would suggest that less developed countries will only grow faster than rich ones if they are further away from their steady state than rich ones are from their respective steady state.

An approach to take into account conditional convergence is by augmenting Equation (5) by additive dummy variables to capture country specific effects. Two dummy variables, $D_{H}$ and $D_{L}$, were used to incorporate differences between countries with high or low steady state respectively (Note 14).

\subsection{Assuming Effect of Spatial Interaction}

Furthermore, the conditional convergence rate in Equation (5) is subject to an upward bias estimation because of a spatial dimension. In general, the presence of spatial effects is likely to lessen the estimated speed of convergence because countries in a relatively prosperous and stable neighbourhood have better chance to record higher per capita income than countries surrounded by poorer regions. A possible consequence could be that firms tend to invest more in central regions than in the periphery, and, hence, regional inequalities tend to increase over time (Note 15). Therefore, countries are likely to be interdependent, which conflicts with the assumptions under which estimations of $\beta$ are made. In this study, we also account for spatial dimensions by assuming that the growth rate of one country also depends upon the income level of surrounding countries recorded in the initial year of the periods under study.

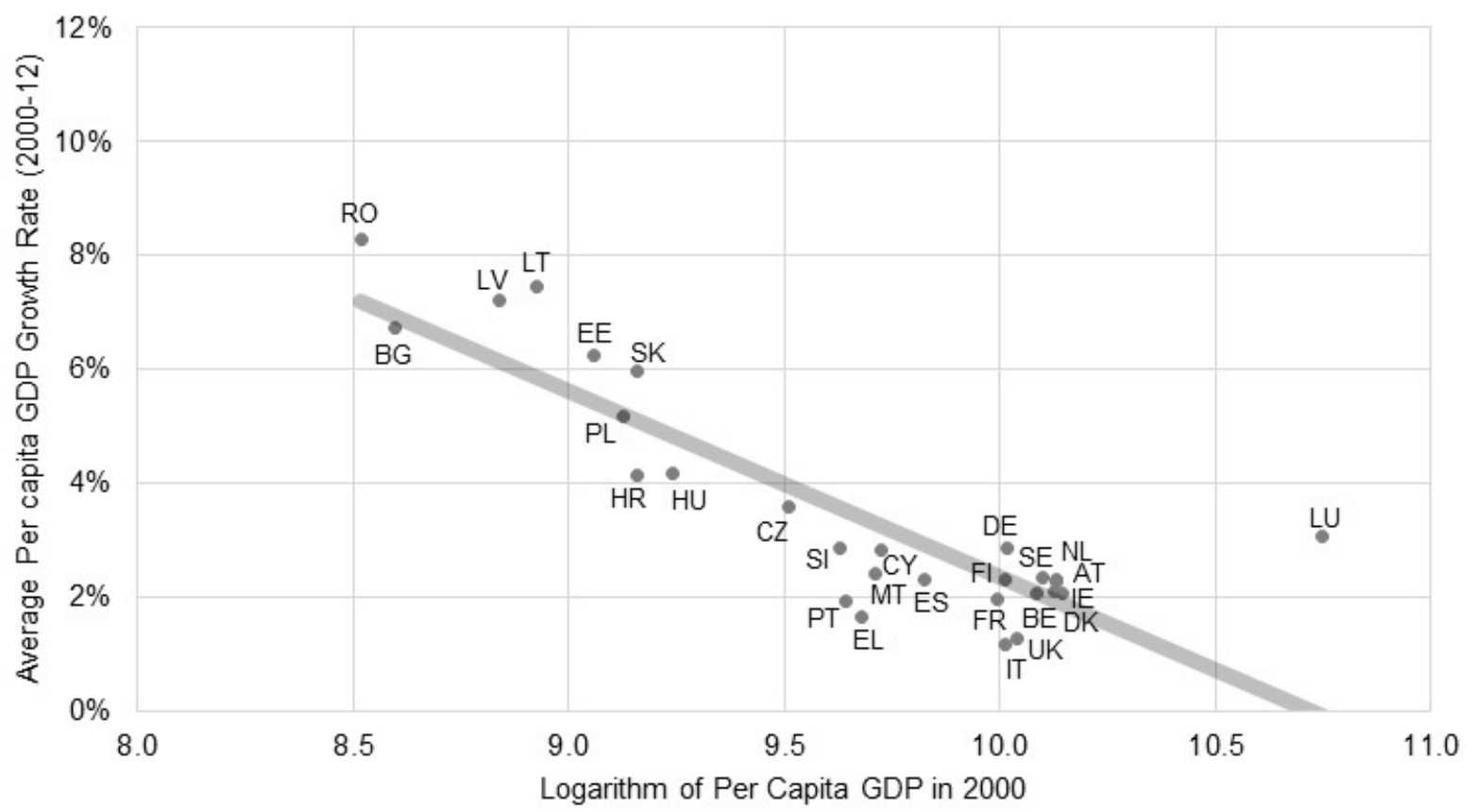

Figure 2a. Convergence of per capita GDP in PPS terms, 2000-2012 


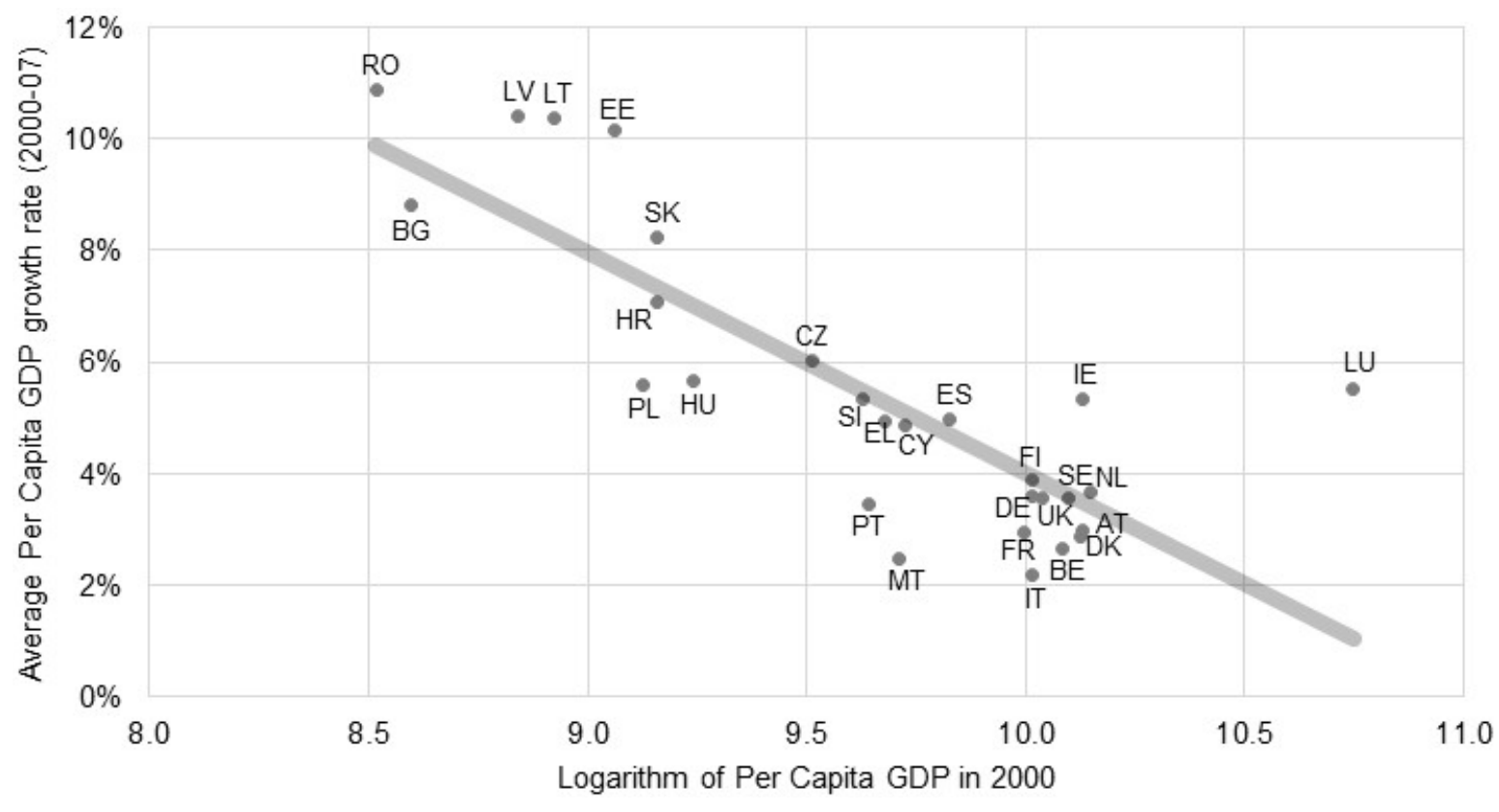

Figure 2b. Convergence of per capita GDP in PPS terms, 2000-2007

\subsection{Accounting for Current Account Imbalances in the Pre-Crisis Period}

According to the neoclassical theory, net capital flows from advanced to developing countries, such that converging countries are expected to run current account deficits. The liberalisation of the capital account and the financial globalisation have spurred the contribution of capital flows to economic growth. In fact, according to Blanchard and Giavazzi (2002), current account balances are responsive to the level of per capita income in the EU. As a result, poor countries would record current account deficits and rich countries would record current account surpluses.

The economic crisis has put into question the effect of macroeconomic imbalances on the convergence rate due to the macroeconomic problems of several European countries. While current account deficits have facilitated a faster pace of convergence, they have also generated adverse effects. One example is the creation of credit booms, which is a result of persistent and excessive current account imbalances built up prior to the crisis (Lane \& Milesi-Ferretti, 2011).

In this respect, it can be postulated that during the pre-crisis era developing countries have maintained real convergence, however, along with excessive current account deficits . Lane and Pels (2012) confirm that the excessive current account deficits have contributed to high per capita economic growth. This can be tested by introducing an interactive dummy term in Equation (5) for member states exceeding the lower threshold of -4\% of GDP based on the average period (Note 16, Note 17). If the coefficient on the interactive term is positive and statistically significant, the existence of such effect on convergence can be confirmed.

\section{Estimation Results}

\section{$5.1 \beta$ Convergence}

The following equation was used to estimate the factors that influence per capita GDP growth

$$
\frac{1}{T} \ln \frac{y_{i T}}{y_{i, 0}}=\alpha_{0}+\alpha_{1} \ln y_{u, 0}+\alpha_{2} \ln y_{i, 0} \cdot M T+\alpha_{3} D_{H}+\alpha_{4} D_{L}+\varepsilon_{i, t}
$$

where the variables have the same meaning as in Equation (5). The same equation was also augmented with a multiplicative dummy variable for Malta, $M T$, and with two additive dummy variables, $D_{H}$ and $D_{L}$, to take into account conditional convergence (Note 18). The subscript $i$ refers to the $i$ th country, and is an error term.

The parameters of Equation (9) were estimated by the Ordinary Least Squares (OLS) Method. It was estimated first by assuming that there is no spatial interaction across the EU, which means that economic growth in a country does not depend on economic growth in neighbouring countries. From the available data, the estimation 
results are as follows

Table 2. Test of $\beta$ convergence for the EU28

\begin{tabular}{lcc}
\hline & $\begin{array}{c}\text { Average Growth Rate } \\
(2000-2007)\end{array}$ & $\begin{array}{c}\text { Average Growth Rate } \\
(2000-2012)\end{array}$ \\
\hline \multirow{2}{*}{ Intercept } & $0.5309^{*}$ & $0.2923^{*}$ \\
& $(15.221)$ & $(13.561)$ \\
$\ln y_{2000}$ & $-0.0494^{*}$ & $-0.0269^{*}$ \\
& $(-13.626)$ & $(-12.161)$ \\
$\ln y_{2000^{*}} M T$ & $-0.0027^{*}$ & -0.0007 \\
& $(-2.794)$ & $(-1.120)$ \\
$D_{H}$ & $0.0392^{*}$ & $0.0205^{*}$ \\
& $(5.240)$ & $(6.523)$ \\
$D_{L}$ & $-0.0207^{*}$ & $-0.0131^{*}$ \\
R-Squared & $(-3.572)$ & $(-2.990)$ \\
Adjusted R-Squared & 0.896 & 0.931 \\
\end{tabular}

* Estimates are statistically different from zero at $1 \%$ level

The estimated parameters are in line with a priori expectations and have plausible magnitudes. The numbers in parentheses are the estimated $t$-values and indicate that the estimates are statistically different from zero at the $95 \%$ level-with the exception of the coefficient for $M T$ which is not statistically different from zero during the 2000 to 2012 period-whereas the correlation coefficient is on the high side. The estimations suggest that in the pre-crisis period Malta converged at $5.7 \%$ per annum, 0.4 percentage points slower than the EU average (6.1\%). Half-life of convergence is approximately 11 years for EU, meaning that it would take about 11 years for half of the initial national income levels' differences to vanish in EU28 (Note 19). This is, however, dependent on the respective gap between present income level and steady state level for each member state. Meanwhile, the time necessary for Malta to halve income inequalities with EU28 level is, on average, 12 years.

Table 2 also shows that for the period 2000-2012, the conditional convergence rate across the EU member states has been $3.2 \%$, while the rate of convergence for Malta is not statistically significant different from EU average. Half-life of convergence is 22 years, due to a slower convergence rate. This suggests that the convergence rate is sensitive to the chosen period given that the convergence process encountered various shocks over the last years amid the financial and economic turmoil.

\section{$5.2 \beta$ Convergence: Introducing Effects of Spatial Dimension}

The equation was re-estimated by controlling for those countries whose growth rate was affected by production activity in the surrounding countries, as otherwise the convergence rate in the omission of spatial dimension is likely to produce biased results. It was assumed, in line with standard macroeconomic theory, that average growth rate also depends upon the starting income level of neighbouring EU member states, $Y_{\text {NEIGH, 2000. The }}$ results are presented in Table 3. 
Table 3. Test of $\beta$ convergence for the EU28, accounting for spatial dimension

\begin{tabular}{lcc}
\hline & $\begin{array}{c}\text { Average Growth Rate } \\
(2000-2007)\end{array}$ & $\begin{array}{c}\text { Average Growth Rate } \\
(2000-2012)\end{array}$ \\
\hline \multirow{2}{*}{ Intercept } & $0.5870^{*}$ & $0.3309^{*}$ \\
& $(15.272)$ & $(12.408)$ \\
$\ln y_{2000}$ & $-0.0384^{*}$ & -0.0209 \\
& $(-7.040)$ & $(-6.107)$ \\
$\ln y_{2000^{*}} M T$ & $-0.0021^{* *}$ & -0.0004 \\
& $(-2.327)$ & $(-0.644)$ \\
$\ln y_{\text {NEIGH, } 2000}$ & $-0.0389^{* *}$ & $-0.0230^{* *}$ \\
$D_{H}$ & $(-2.531)$ & $(-2.183)$ \\
& $0.0375^{* *}$ & $0.0191^{*}$ \\
$D_{L}$ & $(5.536)$ & $(6.433)$ \\
R-Squared & $-0.0190^{* *}$ & $-0.0156^{*}$ \\
Adjusted R-Squared & $(-3.626)$ & $(-3.694)$ \\
\hline
\end{tabular}

* Estimates are statistically significant from zero at $1 \%$ level

** Estimates are statiscally significant from zero at $5 \%$ level

All estimates are in line with a priori expectations in terms of signs and have plausible magnitudes. Again, the pertaining $t$-statistics indicate that the parameters are statistically different from zero, and the coefficient on $M T$ is not statistically different from zero during the period 2000-2012, suggesting that there are no separate convergence rates between Malta and EU28 when taking into account the whole period.

The estimated coefficient on initial income confirms the presence of conditional convergence when accounting for spatial dimension effects. The value of $\alpha_{2}$ indicates that in the pre-crisis period the rate of convergence for Malta is $4.2 \%$, which is slower than EU28 average of $4.5 \%$. Consequently the half-life of convergence in EU28 is 15 years, though this is subject to the idiosyncratic steady state positions. The half-life for Malta is 17 years. Furthermore, the coefficient on neighbours' level of income shows that EU member states are likely to be interdependent to their neighbouring countries. Meanwhile, from 2000 to 2012, the conditional rate of convergence has been $2.4 \%$ per annum with an estimated half-life of 29 years.

The conditional rate of convergence can still be considered 'fast', following the inclusion of neighbours' level of income. The reason for this is, as Gezici and Hewings (2007) point out, if growth rates of lagging countries are higher than growth rates in richer ones, the spatial inequality may decrease over time, and hence results in convergence. In cases where countries pursue their own growth-promoting policies, spill-over effects may exist from that country to adjacent countries. In addition, the existence of the Cohesion Fund, which is largely a redistribution policy with the aim to reduce economic and social disparities, transfers funds going from richer to poorer regions of Europe. As a result, cohesion policies are aimed at increasing investment to achieve higher growth in the periphery, a process which potentially offsets off spatial effects.

\section{$5.3 \beta$ Convergence: Accounting for Current Account Imbalances}

The fast speed of convergence for the period 2000-2007 could be the result of excessive current account deficits which contributed to high per capita economic growth. Given that current account imbalances have negative connotations with respect to sustainability and may have played a role in the economic crisis it is important to confirm if countries like Malta would still have slower pace of convergence in the pre-crisis period if we account for these imbalances.

The econometric model estimated in Table 4 shows that during the period 2000-2007 excessive current account deficits helped countries with low per capita income to converge faster. This reflects the situation mainly in the $\mathrm{CEE}$ countries which recorded both high rates of economic growth and current account deficits. As expected, the 
rate of convergence is slower when accounting for current account deficits, at $4.5 \%$ for the EU average and $4.2 \%$ for Malta. Meanwhile, the convergence pace for Malta remains slower relative to EU28. By contrast, if the 2000-2012 period is assumed, the sign on the current account parameter is positive, though not statistically significant from zero; meaning that no conclusive evidence can be drawn on the effect of excessive current account deficits. This is possibly due to the fact that although larger current account deficits would support a faster pace of real convergence, possible severe macroeconomic risks would damage the performance of the member states concerned. Indeed, the change in the performance of countries with excessive current account deficits have been generally weaker post-2007 compared to countries with more favourable balance.

Table 4. Test of $\beta$ convergence for the EU28, accounting for spatial dimension and current account imbalances

\begin{tabular}{lcc}
\hline & $\begin{array}{c}\text { Average Growth Rate } \\
(2000-2007)\end{array}$ & $\begin{array}{c}\text { Average Growth Rate } \\
(2000-2012)\end{array}$ \\
\hline Intercept & $0.5286^{*}$ & $0.3721^{*}$ \\
& $(10.526)$ & $(10.429)$ \\
$\ln y_{2000}$ & $-0.0358^{*}$ & $-0.0238^{*}$ \\
& $(-6.602)$ & $(-6.394)$ \\
$\ln y_{2000} * M T$ & $-0.0027^{*}$ & $1.71 \mathrm{E}-06$ \\
& $(-2.887)$ & $(-0.003)$ \\
$\ln y_{\text {NEIGH, } 2000}$ & $-0.0316^{* *}$ & $-0.0256^{* *}$ \\
$\ln y_{2000} * D_{C A}$ & $(-2.060)$ & $(-2.500)$ \\
& $0.0008^{* * *}$ & $-0.0006^{* * *}$ \\
$D_{H}$ & $(1.714)$ & $(-1.663)$ \\
& $0.0333^{*}$ & $0.0192^{*}$ \\
$D_{L}$ & $(4.810)$ & $(6.703)$ \\
R-Squared & $-0.0219 *$ & $-0.0148^{*}$ \\
Adjusted R-Squared & $(-4.131)$ & $(-3.611)$ \\
\hline
\end{tabular}

* Estimates are statistically significant from zero at $1 \%$ level

** Estimates are statiscally significant from zero at 5\% level

*** Estimates are statiscally significant from zero at $10 \%$ level

All equations performed satisfactorily in terms of residual diagnostic tests, regarding heteroscedasticity, for which the Jarque-Bera and White tests were used; which showed that the residuals are normally distributed and there is no evidence of heteroscedasticity at $95 \%$ confidence interval respectively. Regarding multicollinearity, the correlation between exogenous variables across countries was not found to be unduly high (Note 20).

\section{$5.4 \sigma$ Convergence}

Despite the structural imbalances across EU countries, incomes of less developed countries have tended to converge to those of EU15. The pattern of convergence is illustrated in Figure 3, which shows the CV of per capita GDP in PPS between NMS, Malta and EU15 average. 


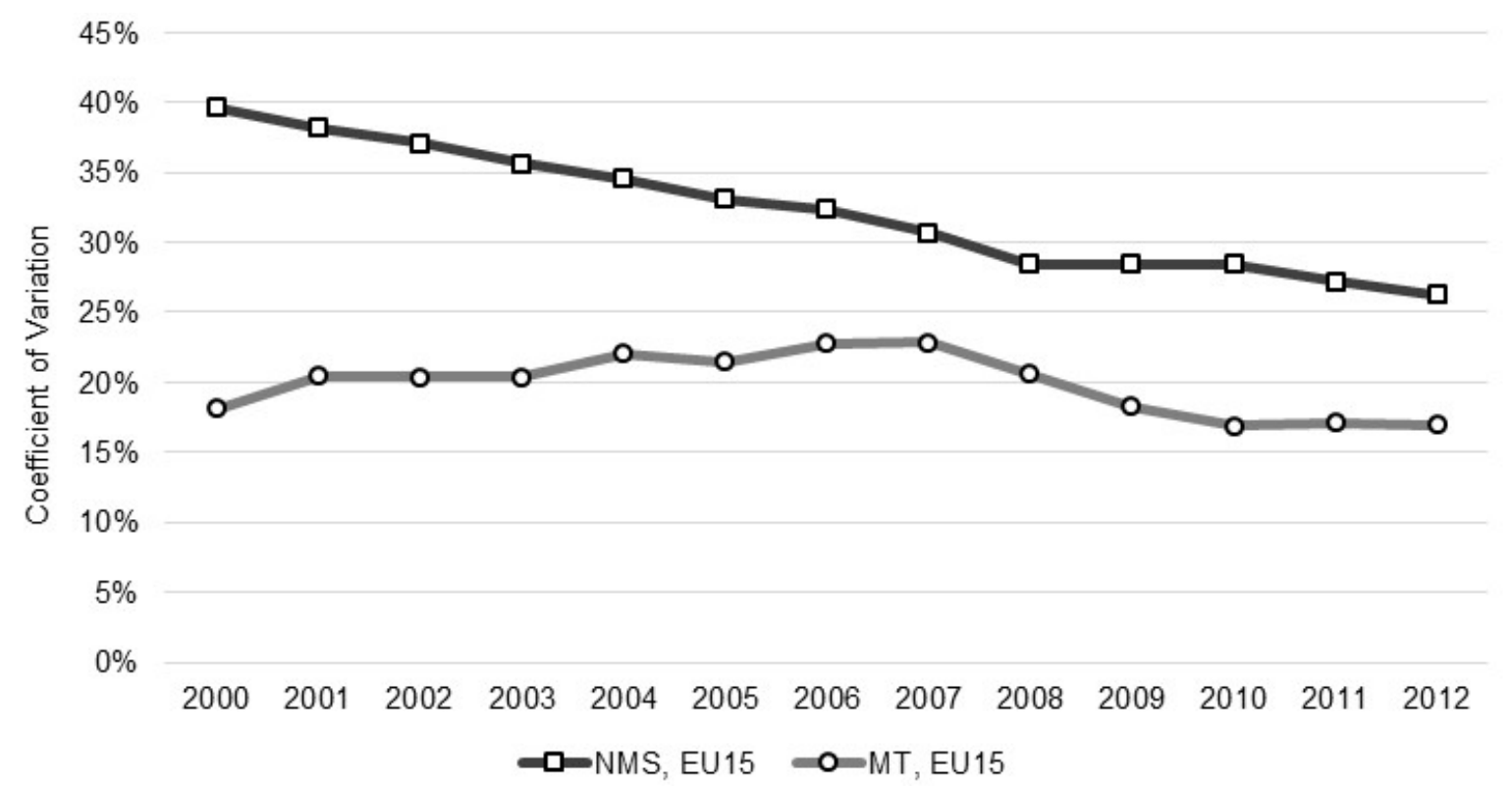

Figure 3. Coefficient of Variation, 2000-2012

The CV between NMS and EU15 has, on average, decreased between 2000 and 2012 from $39.6 \%$ to $26.3 \%$. Indeed, during the period 2000-2012, NMS grew at a pace that was twice as higher than the former EU15 countries. On the contrary, the income gap between Malta and EU15 widened between 2000 and 2007 because EU15 countries, on average, grew by a larger multiple compared to Malta. This means that the divergence process did not contract after EU accession in 2004.

$\sigma$ convergence is confirmed by estimating Equation (7). Table 4 shows that the negative parameter of the linear time trend is statistically significant at the $1 \%$ level for NMS, meaning that the standing of various member states has narrowed over time in the extent of income differential. This verifies that for most years a tendency for convergence was recorded. Table 4 also confirms that $\sigma$ convergence is inconclusive for Malta. Indeed the parameter of the linear time trend is small and not significantly different from zero, meaning that there is no stable tendency exhibited by both divergence and convergence during the period in consideration.

Table 4. Linear estimation of coefficient of variation, 2000-2012

\begin{tabular}{lcc}
\hline & $\begin{array}{c}\text { Coefficient of variation of per capita } \\
\text { GDP between NMS and EU15 }\end{array}$ & $\begin{array}{c}\text { Coefficient of variation of per } \\
\text { capita GDP between MT and } \\
\text { EU15 }\end{array}$ \\
\hline Intercept & $0.4022^{*}$ & $0.2163^{*}$ \\
Linear Time Trend & $(103.318)$ & $(18.087)$ \\
R-Squared & $-0.0113^{*}$ & -0.0025 \\
Adjusted R-Squared & $(-23.010)$ & $(-1.661)$ \\
\hline
\end{tabular}

* Estimates are statistically significant from zero at $1 \%$ level

\section{Conclusion}

This paper argues that that less developed countries grow faster than rich ones, mainly because they are further away from their idiosyncratic steady state. In turn this gives rise to higher per capita GDP growth rates. This hypothesis was tested using a neoclassical exogenous growth approach based on a Cobb-Douglas production function, utilising annual growth rates for member states of the European Union. 
Among other things, the results indicate that economies that are far below their steady state values grow faster than economies which are not far from their steady state. The speed of conditional convergence for Malta to reach its respective steady state is slower than EU average, meaning that the time to close half the income gap with EU28 is relatively higher. Therefore, the results suggest that conditional convergence for the Maltese economy is not slow because of a high starting level of per capita income among NMS, but because Malta possibly has a narrow income gap to its low steady-state level. The fact that convergence is stronger in NMS is supported by the fact that NMS with comparatively lower per capita income have been reducing their income gap with EU15, whereas Malta, on average, remained stable.

This finding has important implication for Malta mainly that although it has been converging to its respective steady state it has not reduced income gap significantly with EU15. This evidence suggests that the speed of convergence has been insufficient to close the income gap; implying that while a convergence rate is necessary, it is not enough to reduce income disparity.

Another implication is that economic cohesion depends on particular factors-such as gross fixed capital formation and labour force participation-which determine how far an economy is from its steady state level. Indeed, low levels of gross fixed capital formation and labour force participation may explain the slow convergence process. Therefore, an increase in the investment rate and higher labour force participation rates render a higher steady state level of output per capita and a higher economic growth during the transitional phase. In this respect, factors directly linked with economic convergence, like good governance, macroeconomic stability, and reform policy initiatives are relevant.

Meanwhile, technological progress has also important implications on output growth in the long-run; such that long-run growth depends on the total factor productivity and the effectiveness of resources used. In this regard, fertility and appropriability of research have both an important role in advancing technological progress and output in Malta.

The results should be taken into account in the discussions about the allocation of EU Cohesion Fund. The financial support to transitional countries ( $75 \%$ to $90 \%$ of the EU average GDP) should not be reduced, but, rather, sustained in order to facilitate the catching-up process. At the same time, further efforts are called for to help periphery member states overcome difficulties involved in the transitional phase.

Another important challenge lay ahead is the adherence of EU28 to the euro area. Although adherence to the euro area officially implies the fulfilment of nominal convergence criteria, economic convergence process is needed for the sustainable development of the enlarged euro area in the long term. The presence of asymmetry in EU28 by convergence to different steady state values necessitates flexibility in markets to a make a smoothly functioning optimal currency area possible.

Disparities in income levels, within reason, may always exist. However, any country with low per capita income should close as much as possible income gaps compared to richer countries. Over the years, unlike other developing countries, Malta's low level of per capita income did not translate into faster per capita growth rates, even after EU accession. Therefore policies and reforms oriented towards raising potential output, through investment, and improving the productive capability of the country, particularly through the raising of skill levels, the promotion of lifelong learning, and the raising of the labour force participation rates are called for. Indeed, for many economies, the prospect of acceding to the EU has been a powerful spur to reform.

\section{Acknowledgments}

The views and opinions in this paper are those of the author only. The author would like to express his appreciation to Gevit Duca and Daniel Gravino for their valuable and constructive suggestions during the planning and development of this research work. Comments by Angela Buttigieg, Gilmour Camilleri, Godwin Mifsud, and Kevin Vella helped to improve an earlier version of this manuscript.

\section{References}

Barro, R. J., \& Sala-i-Martin, X. (1991). Convergence across states and regions. Brookings Papers on Economic Activity, 107-182.

Barro, R. J., \& Sala-i-Martin, X. (1992). Convergence. Journal of Political Economy, 100(2), 223-251.

Barro, R. J., \& Sala-i-Martin, X. (2003). Economic growth. Cambridge and London: The MIT Press.

Basile, R., De Nardis, S., \& Girardi, A. (2001). Regional inequalities and cohesion policies in the European Union. Rome: ISAE Istituto di Studi e Analisi Economica. http://dx.doi.org/10.2139/ssrn.936319 
Baumol, W. J. (1986). Productivity growth, convergence, and welfare: What the long-run data show. The American Economic Review, 76(5), 1072-1085.

Blanchard, O., \& Giavazzi, F. (2002). Current account deficits in the euro area: The end of the Feldstein-Horioka puzzle? Brookings Papers on Economic Activity, 2002(2), 147-209.

Briguglio, L. \& Vella, M. (2015). Labour demand in the EU and returns to scale: A production function approach. The Journal of International Trade \& Economic Development, Advanced publication. http://dx.doi.org/10.1080/09638199.2014.1002414

Briguglio, L. (2011). Macroeconomics and the Maltese Economy. Malta: BDL Publishing.

Chapsa, X., \& Katrakilidis, C. (2014). Assessing economic convergence in the EU: Is there a perspective for the 'cohesion countries'? Applied Economics, 46(33), 4025-4040. http://dx.doi.org/10.1080/00036846.2014.946185

De Long Bradford, J. (1988). Productivity growth, convergence, and welfare: Comment. The American Economic Review, 78(5), 1138-1154.

Eckey, H., \& Türck, M. (2005). Convergence of EU-regions: A literature report.Volkswirtschaftliche Diskussionsbeiträge.

Eickmeier, S., \& Breitung, J. (2006). How synchronized are new EU member states with the euro area? Evidence from a structural factor model. Journal of Comparative Economics, 34(3), 538-563. http://dx.doi.org/10.1016/j.jce.2006.06.003

Firgo, M., \& Huber, P. (2014). Convergence as a heterogeneous process: What can be learnt about convergence in EMU from regional experiences? Empirica, 41(2), 129-151. http://dx.doi.org/10.1007/s10663-013-9242-y

Gezici, F., \& Hewings, G. J. (2007). Spatial analysis of regional inequalities in Turkey. European Planning Studies, 15(3): 383-403. http://dx.doi.org/10.1080/09654310601017091

Hájková, D., \& Hurník, J. (2007). Cobb-Douglas production function: the case of a converging economy. Czech Journal of Economics and Finance, 57(9-10), 465-476. http://dx.doi.org/10.4236/ojs.2013.33019

Jiang, Y. (2014). Openness, Economic Growth and Regional Disparities. New York: Springer. http://dx.doi.org/10.1007/978-3-642-40666-9

Kaitila, V. (2004). Convergence of Real GDP per capita in the EU15. How do the Accession countries fit in? European Network of Economic Policy Research Institutes Working Paper, 25.

Krugman, P. (1991). Increasing returns and economic geography. Journal of Political Economy, 99(31), 183-199.

Krugman, P. (1993). On the number and location of cities. European Economic Review, 37(2), 293-298. http://dx.doi.org/10.1016/0014-2921(93)90017-5

Lane, P. R., \& Milesi-Ferretti, G. M. (2011). The cross-country incidence of the global crisis. IMF Economic Review, 59(1), 77-110. http://dx.doi.org/10.5089/9781455201822.001

Lane, P. R., \& Pels, B. (2012). Current account imbalances in Europe. Centre for Economic Policy Research.

Mankiw, N. G., Romer, D., \& Weil, D. N. (1992). A contribution to the empirics of economic growth. The Quarterly Journal of Economics, 107(2), 407-437.

Marques, H. (2011). Asymmetries in heterogeneous integrated areas: Evidence from sectoral trade between old and new EU members. The Journal of International Trade \& Economic Development, 20(1), 5-29. http://dx.doi.org/10.1080/09638199.2011.538181

Marrocu, E., Paci, R., \& Usai, S. (2013). Productivity growth in the Old and New Europe: The role of agglomeration externalities. Journal of Regional Science, 53(3), 418-442. $\mathrm{http}: / / \mathrm{dx}$.doi.org/10.1111/jors. 12000

Monfort, P. (2009). Regional convergence, growth and interpersonal inequalities across EU. Brussels: Directorate General Regional Policy European Commission.

Neven, D., \& Gouymte, C. (1995). Regional convergence in the European Community. Journal of Common Market Studies, 33(1), 47-65. 
Niebuhr, A., \& Schlitte, F. (2004). Convergence, trade and factor mobility in the European Union-implications for enlargement and regional policy. Intereconomics, 39(3), 167-176. http://dx.doi.org/10.1007/BF02933584

Paas, T., \& Schilitte, F. (2006). Regional income inequality and convergence processes. ERSA conference papers: European Regional Science Association.

Prochniak, M. (2008). Real economic convergence between Central and Eastern Europe and the European Union, China's Three Decades of Economic Reform (1978-2008). Chinese Economic Association, Cambridge, 1-2 April.

Reiner, M. (1999). Regional convergence in the EU: Determinants for catching-up or staying behind. Review of Regional Research, 19(2), 157-181.

Romer, P. M. (1990). Human capital and growth: Theory and evidence. Carnegie-Rochester Conference Series on Public Policy, 32(0), 251-286. http://dx.doi.org/10.1016/0167-2231(90)90028-J

Shen, D., Wang., R., \& Yi, N. (2008). Analysis of the Convergence of Regional Economic Growth in Beijing. International Journal of Business and Management, 3(10), 52-58. http://doi.dx.org/10.5539/ijbm.v3n10p52

Solow, R. M. (1956). A contribution to the theory of economic growth. The Quarterly Journal of Economics, 70(1), 65-94.

Tamura, R. (1991). Income convergence in an endogenous growth model. Journal of Political Economy, 99(3), 522-540.

Varblane, U., \& Vahter, P. (2005). An Analysis of the Economic Convergence Process in the Transition Countries. University of Tartu-Faculty of Economics \& Business Administration Working Paper Series, 37.

Vojinović, B., \& Oplotnik, Z. (2008). Real Convergence in the EU Member States. Prague Economic Papers, 1(1), 23-39.

Vojinović, B., Oplotnik, Ž. J., \& Próchniak, M. (2010). EU enlargement and real economic convergence. Post-Communist Economies, 22(3), 303-322. http://doi.dx.org/10.1080/14631377.2010.498681

\section{Notes}

Note 1. In many studies, the worldwide speed of convergence is estimated at approximately $2 \%$ per annum (Barro and Martin, 2003; Vojinović, 2005). In contrast, studies that focused on EU member states report a faster rate of convergence. The many authors who addressed this issued include Neven and Gouyette (1995), Basile et al. (2001), Niebuhr and Schlitte (2004), and Eckey et al. (2005)

Note 2. Paas and Schlitte (2006) argue that a significant process of divergence is evident across regions in the new member states. Perhaps this is because the catching-up by the less developed new member states at the national level seems to be mainly driven by a few high growth regions.

Note 3. The new member states include Cyprus, Czech Republic, Estonia, Hungary, Latvia, Lithuania, Malta, Poland, Slovakia, and Slovenia, which acceded to the EU in 2004; Bulgaria, and Romania which were admitted in 2007; and Croatia, which joined the EU in 2013.

Note 4. PPS is a method of adjustment used to allow for international comparisons of GDP.

Note 5. CEE countries include Bulgaria, Croatia, Czech Republic, Estonia, Hungary, Latvia, Lithuania, Poland, Romania, Slovakia and Slovenia.

Note 6. Luxembourg has an unexceptionally large output-to-resident population ratio because of high net number of cross-border workers compared to resident population. GDP is measured on domestic concept, which covers all persons engaged in some productive activity that falls within the production boundary system irrespective of the place of residence of the employed person. Therefore this gives a large per capita GDP which is not necessarily reflected in the income of resident households for Luxembourg.

Note 7. In 2001 Malta recorded an exceptional performance with respect to investment outlays in machinery and drop in export performance. Weak domestic demand contributed to subdued economic activity in 2004, while intensified international competition has affected negatively the domestic economy, in particular certain manufacturing sectors, as well as on the tourism industry. Another constraint involves the high costs per unit, which was strongly determined by increasing energy prices. In 2011, the catch-up gap rate improved considerably possibly because Malta was not directly and unduly affected by the international financial crisis. 
For more details see the various issues of the Economy Survey, published by the Economic Policy Department.

Note 8: The neoclassical Cobb-Douglas production function assumes positive and diminishing marginal returns with respect to inputs of labour and capital, and constant returns to scale. This restricts the income share of labour in production to be stable over time. The time frame is relatively short so that the assumption that labour share in production is constant is compelling. On this issue see Hájková, and Hurník (2007).

Note 9 . The coefficient of variation is obtained by dividing the standard deviation of the series by the average of the sample.

Note 10. The approach presented by Baumol (1986) was expanded by Barro and Sala-i-Martin (1992) in which they derived a logarithmic linearisation of the transitional dynamics of the equation around the steady state.

Note 11. The available Eurostat statistics do not enable the author to obtain GDP per capita for all EU28 prior to 2000.

Note 12. The average growth rate of real GDP per capita is computed by taking the log-difference of real GDP per capita, $g$, divided by the number of years, $T$. In continuous time series it is assumed that $Y_{t}=Y_{0} e^{g T}$. Therefore $g=\left(\ln Y_{t}-\ln Y_{0}\right) / T$.

Note 13. Some authors argue that the EU is a heterogeneous integrated area with respect to country size, income levels, relative factor endowments, and different history of economic systems. This has been widely debated to assess whether the EU can be considered as an optimal currency area.

Note 14. The method adopted for the inclusion of dummy variables in this study was based upon considerable amount of empirical experimentation. The objective of this experimentation was to test whether Equation (5) shifted in a statistically significant manner for some countries (Shen et al., 2008, Jiang, 2014). Using an iterative procedure, based on statistical tests of significance, and plausibility of the signs of the estimated coefficients, dummy variables were assigned the value of unity for countries when a shift was assumed to take place, and with a value of zero for the remaining countries. The final choice was made on the basis of the best correlation and residual diagnostic tests. Under 2000-2007 period, $D_{H}$ included Ireland and Luxembourg, and $D_{L}$ included Hungary, Poland and Portugal. Whilst under 2000-2012 period, Latvia, Lithuania, Luxembourg, Romania and Slovakia were included in $D_{H}$, and Greece and Italy were included in $D_{L}$.

Note 15 . Some scholars argue that growth is indeed a spatially cumulative process, a factor that is likely to increase disparities (Krugman, 1991, 1993). However, some retaliate that on the existence of economies of scale it leads to a large degree of intra-industry trade and, consequently, convergence rate can be higher still for the poorest regions of Europe (Monfort, 2009). Overall, a clear-cut conclusion is difficult to formulate as concentration and agglomeration effects can be brought about by economic integration, however, as economic integration proceeds economic activity transgresses one or more borders and national borders become increasingly less relevant.

Note 16. The European Commission calculates current account imbalances as an arithmetic average over 3 years within the interval $-4 \%$ and $6 \%$ of GDP. For more details see the MIB Scoreboard.

Note 17. Although current account imbalances could be the result of both deficits and surpluses, the emphasis of this study remains on the negative current account balances (less than or equal to $-4 \%$ of GDP) which brings into debate the issues of external debt and financing capacity. $D_{C A}$ included Bulgaria (-9.0\%), Croatia (-5.2\%), Cyprus (-7.1\%), Estonia (-6.9\%), Greece (-9.0\%), Hungary (-5.1\%), Latvia (-7.9\%), Lithuania (-5.8\%), Malta $(-5.2 \%)$, Poland (-4.3\%), Portugal (-9.1\%), Romania, (-6.8\%), Slovakia (-5.2\%) and Spain (-5.4\%).

Note 18. The $\beta$ convergence for Malta can be calculated as follows: $\beta=-\left[1 / T * \ln \left(1-\left(\alpha_{2}+\alpha_{1}\right)\right) T\right]$. This implies that when $\alpha_{2}$ is negative $\beta$ convergence for Malta is slower than the EU average.

Note 19. When time-series data are used the half-life is the time required to halve the initial gap between steady state and actual per capita GDP. If $\ln y_{t}{ }^{*}=\ln y_{0} \mathrm{e}^{-\beta t}+\left(1-\mathrm{e}^{-\beta t}\right) \ln y_{t}{ }^{*}$, the time $t$ for which $\ln y_{t}$ is half way between $\ln y_{0}$ and $\ln y_{t}{ }^{*}$ (steady state level) satisfies the condition $\mathrm{e}^{-\beta t}=0.5$. Although the half-life value is usually applied to time-series data, the concept of half-life in cross-section analysis shall be used to calculate the number of years to halve income disparity across countries-being EU28 average.

Note 20. Equation (5) was also estimated to calculate the absolute speed of convergence. For the 2000-2007 and 2000-2011 periods, the absolute $\beta$ convergence rates are $2.4 \%$ and $1.4 \%$ respectively, after controlling for spatial growth rates. 


\section{Appendix A: Data Appendix}

GDP per capita in PPS, 2000-2012

\begin{tabular}{|c|c|c|c|c|c|c|c|c|c|c|c|c|c|}
\hline & 2000 & 2001 & 2002 & 2003 & 2004 & 2005 & 2006 & 2007 & 2008 & 2009 & 2010 & 2011 & 2012 \\
\hline Austria & 25,100 & 24,900 & 26,000 & 26,400 & 27,600 & 28,100 & 29,700 & 30,900 & 31,100 & 29,500 & 30,900 & 32,300 & 30,700 \\
\hline Belgium & 24,000 & 24,500 & 25,600 & 25,600 & 26,200 & 26,900 & 27,800 & 28,900 & 28,900 & 27,600 & 29,400 & 30,200 & 12,100 \\
\hline Bulgaria & 5,400 & 5,900 & 6,500 & 6,900 & 7,500 & 8,200 & 9,000 & 10,000 & 10,900 & 10,300 & 10,800 & 11,700 & 20,700 \\
\hline Croatia & 9,500 & 10,000 & 11,100 & 11,700 & 12,500 & 13,200 & 14,100 & 15,600 & 16,200 & 14,900 & 14,700 & 15,200 & 32,100 \\
\hline Cyprus & 16,700 & 17,800 & 18,100 & 18,300 & 19,600 & 20,800 & 22,000 & 23,500 & 24,800 & 23,400 & 23,600 & 23,500 & 31,500 \\
\hline Czech Republic & 13,500 & 14,400 & 15,000 & 15,800 & 16,900 & 17,800 & 18,900 & 20,600 & 20,200 & 19,400 & 19,700 & 20,300 & 18,200 \\
\hline Denmark & 25,000 & 25,200 & 26,200 & 25,700 & 27,100 & 27,700 & 29,300 & 30,600 & 31,100 & 28,900 & 31,200 & 31,500 & 32,900 \\
\hline Estonia & 8,600 & 9,200 & 10,200 & 11,300 & 12,400 & 13,800 & 15,600 & 17,500 & 17,200 & 14,900 & 15,600 & 17,400 & 19,500 \\
\hline Finland & 22,300 & 22,700 & 23,500 & 23,300 & 25,100 & 25,700 & 26,900 & 29,300 & 29,700 & 26,900 & 27,900 & 29,000 & 24,400 \\
\hline France & 21,900 & 22,800 & 23,600 & 23,000 & 23,700 & 24,700 & 25,500 & 26,900 & 26,700 & 25,500 & 26,600 & 27,400 & 27,700 \\
\hline Germany & 22,400 & 22,900 & 23,400 & 23,900 & 25,000 & 26,000 & 27,300 & 28,800 & 29,000 & 26,900 & 29,200 & 30,800 & 15,600 \\
\hline Greece & 16,000 & 17,100 & 18,400 & 19,200 & 20,300 & 20,400 & 21,800 & 22,600 & 23,200 & 22,300 & 21,600 & 20,300 & 25,600 \\
\hline Hungary & 10,300 & 11,500 & 12,500 & 12,900 & 13,600 & 14,200 & 14,900 & 15,300 & 15,900 & 15,300 & 16,100 & 16,900 & 23,400 \\
\hline Ireland & 25,100 & 26,200 & 28,200 & 29,300 & 30,800 & 32,400 & 34,400 & 36,500 & 32,900 & 30,100 & 31,400 & 32,300 & 16,400 \\
\hline Italy & 22,300 & 23,400 & 23,000 & 23,000 & 23,100 & 23,600 & 24,700 & 26,000 & 26,000 & 24,300 & 25,100 & 25,500 & 18,300 \\
\hline Latvia & 6,900 & 7,600 & 8,400 & 9,100 & 10,100 & 11,100 & 12,500 & 14,300 & 14,600 & 12,700 & 13,500 & 15,000 & 17,000 \\
\hline Lithuania & 7,500 & 8,300 & 9,100 & 10,300 & 11,100 & 12,300 & 13,600 & 15,500 & 16,100 & 13,600 & 15,100 & 16,900 & 22,000 \\
\hline Luxembourg & 46,500 & 46,200 & 49,000 & 51,100 & 54,500 & 57,000 & 63,800 & 68,400 & 65,800 & 59,200 & 64,000 & 66,700 & 32,600 \\
\hline Malta & 16,500 & 16,100 & 16,800 & 17,000 & 17,200 & 18,000 & 18,600 & 19,600 & 20,300 & 19,800 & 21,300 & 21,700 & 33,100 \\
\hline Netherlands & 25,500 & 26,400 & 27,200 & 26,700 & 27,900 & 29,300 & 31,000 & 33,000 & 33,500 & 31,000 & 31,700 & 32,500 & 17,100 \\
\hline Poland & 9,200 & 9,400 & 9,900 & 10,100 & 10,900 & 11,500 & 12,300 & 13,600 & 14,100 & 14,200 & 15,400 & 16,400 & 19,400 \\
\hline Portugal & 15,400 & 15,900 & 16,300 & 16,400 & 16,700 & 17,900 & 18,700 & 19,600 & 19,500 & 18,800 & 19,600 & 19,300 & 13,500 \\
\hline Romania & 5,000 & 5,500 & 6,000 & 6,500 & 7,500 & 8,000 & 9,200 & 10,700 & 12,200 & 11,700 & 12,400 & 12,900 & 21,400 \\
\hline Slovakia & 9,500 & 10,300 & 11,100 & 11,500 & 12,300 & 13,500 & 14,900 & 16,900 & 18,100 & 17,000 & 18,100 & 18,900 & 19,400 \\
\hline Slovenia & 15,200 & 15,800 & 16,800 & 17,300 & 18,700 & 19,600 & 20,700 & 22,100 & 22,700 & 20,200 & 20,600 & 21,200 & 29,400 \\
\hline Spain & 18,500 & 19,400 & 20,600 & 20,900 & 21,900 & 22,900 & 24,800 & 26,200 & 25,900 & 24,200 & 24,200 & 24,300 & 32,200 \\
\hline Sweden & 24,300 & 24,200 & 25,000 & 25,700 & 27,300 & 27,300 & 29,000 & 31,200 & 30,900 & 28,200 & 30,200 & 31,400 & 26,600 \\
\hline United Kingdom & 22,900 & 23,900 & 24,800 & 25,400 & 26,900 & 27,800 & 28,900 & 29,400 & 28,600 & 26,300 & 26,300 & 26,400 & 67,100 \\
\hline
\end{tabular}

\section{Copyrights}

Copyright for this article is retained by the author, with first publication rights granted to the journal.

This is an open-access article distributed under the terms and conditions of the Creative Commons Attribution license (http://creativecommons.org/licenses/by/3.0/). 